\title{
Do you know where your fillers go? An ultrastructural investigation of the lips
}

This article was published in the following Dove Press journal:

Clinical, Cosmetic and Investigational Dermatology

20 June 2014

Number of times this article has been viewed

Julia Vent ${ }^{1}$

Florian Lefarth ${ }^{2}$

Thomas Massing ${ }^{3}$

Wolfgang Angerstein ${ }^{2}$

'Department of Otorhinolaryngology, Head and Neck Surgery, University of Heidelberg Medical Center at Mannheim, Mannheim, Germany; ${ }^{2}$ Department of Phoniatrics and Pedaudiology, University of Düsseldorf Medical Center, Düsseldorf, Germany; ${ }^{3}$ Research Laboratory for Medical Acoustics and Audiology, Department of Phoniatrics and Pedaudiology, University of Düsseldorf Medical Center, Düsseldorf, Germany
Correspondence: Julia Vent

Department of Otorhinolaryngology, Head and Neck Surgery, University of Heidelberg Medical Center at Mannheim, Theodor-Kutzer-Ufer I-3, 68167 Mannheim, Germany

Tel +4962I $383 \quad 1600$

Fax +4962I 3833827

Email julia.vent@umm.de; dr.julia.vent@ gmail.com
Aim: To investigate the exact location and position of hyaluronic acid fillers in the perioral region by ultrasound and optical coherence tomography.

Introduction: To date, there are few in vivo investigations in humans on the exact positioning of injectable hyaluronic acid fillers, and severe complications such as hematoma and thromboembolism are rarely addressed.

Materials and methods: There were nine female patients investigated in this pilot study. All of them were periorally injected with hyaluronic acid. The exact product, amount, and locations, as well as the injection techniques, were recorded and compared. Before, immediately after, and 18 days after injection, photo documentation as well as high-resolution ultrasonography and optical coherence tomography of the lip surface were performed.

Results: Minor bruising occurred, which resolved within 7 to 9 days. On day 18, no more hemorrhage could be detected. Injected material distributed well in the tissue, and no embolism or thrombosis occurred. However, the injected material came close (up to $1 \mathrm{~mm}$ ) to important structures such as blood vessels. Lip wrinkles improved, and the lip surface was smoother and more even.

Conclusion: Hyaluronic acid injections can improve aesthetics and reduce fine wrinkles of the lips. In the patients investigated in this study, compression of structures such as vessels and nerve fibers did not occur, nor did any severe complications result from injection. However, one must be aware of serious complications (eg, hematoma, thromboembolism) and the important anatomic structures (eg, orbicularis oris muscle, vessels, and nerves), and injecting physicians should always have hyaluronidase as a rescue medication at hand.

Summary: Hyaluronic acid is a suitable tool for lip augmentation and reduction of fine lines; however, one must be aware of anatomic structures when injecting filler material into the lips and perioral area, and be familiar with the injection techniques.

Keywords: hyaluronic acid, dermal fillers, injectables, augmentation cheiloplasty

\section{Introduction}

\section{Background}

To increase the volume of the lips, a procedure called lip augmentation, or augmentation cheiloplasty, can be performed surgically or by way of a minimally invasive injection of filler material. Increasing the volume, restoring a symmetric ratio of all four lip quadrants, and reducing the fine lines and dryness of the lips are the primary indications for aesthetic cheiloplasty. Indications for augmentation cheiloplasty are to restore facial symmetry, to increase lip volume and fullness, and to improve definition of the vermilion border. Reasons that patients present for augmentation cheiloplasty 
are either medical (asymmetric face after trauma, nerve palsy, or cancer) or aesthetic: patients may want to improve fullness (and may already have a good shape of the lips), enhance atrophy (due to aging or genetics), or increase definition of the vermilion border (associated with smoking, a habit of inverting the lips in stress, and age). ${ }^{1}$

Augmenting the perioral region with injectable fillers is most often performed based on experience and by palpation, without knowledge of the exact, final position of the injected material in vivo. Not all injecting physicians are aware of the crucial subcutaneous structures.

To our knowledge, there is only one in vivo investigation on the exact positioning of injectable fillers, ${ }^{2}$ and reports of severe complications, such as lip hematoma or thromboembolism, are rarely published. ${ }^{3,4}$ The lips, and especially the modiolar region, have strong blood supply ${ }^{5}$ and are thus especially prone to hematoma and injury. ${ }^{6}$

\section{Histological and imaging studies of lip and perioral anatomy}

There is a border line between the perioral epithelium and the red lip vermilion, which, on the upper lip, is called Cupid's bow and always has an individual, characteristic pattern. Portrait artists know this line as "the finger print of a face", which makes every smile unique. The upper lip shows a fine groove, the philtrum. Scar formations change the anatomy and tissue architecture ${ }^{7}$ and have to be considered in lip augmentation because of altered distribution of the filler material.

The histology of the perioral region - as in every type of skin (stratified squamous cell epithelium) - consists of epidermis, dermis, and hypodermis. It contains hair follicles as well as sebaceous and sweat glands and is separated from the underlying tissue by connective tissue and muscles. On the dental side of the lip, there is mucosa with multiple minor salivary glands called labial glands. ${ }^{8,9}$

The red color of the lip margin is due to a translucence from the blood vessels present in the underlying connective tissue papillae. These superficial papillae are rich in blood capillaries and sensory nerve endings, which render the lip highly vascular as well as highly sensitive. No sweat glands or hair follicles are present in the free red margin of the lip.

The muscular basis of the lip and the perioral region consists of the orbicularis oris muscle (OOM), which is subdivided into two parts: the superficial part and the deep part, the deep part itself consists of pars peripheralis and pars marginalis.

The functions of the lips in humans are various: the archaic parts account for sphincter function, food intake (catching food, breaking food, eating, moistening, and tasting), and breathing, whereas the phylogenetically newer parts serve communication through facial expression and speech.

The submuscular aponeurotic system is the anchoring of the OOM and perioral mimic muscle to it cranially, as well as to the platysma caudally. This has been studied by Thaller et al in ten fresh cadaver heads and twelve rhesus monkey fetuses. The authors described this distinct fibromuscular layer and its relation to fascia and muscles, and reported that it serves as a covering as well as connector and anchor between muscles and skin, maintaining tension in the face. ${ }^{10}$

The perioral area is not only well circulated by lymphatic and blood vessels, but also by numerous mimic muscle fibers accounting for vivid facial expression. These mimic muscle fibers intertwine and extend from the superficial part of the OOM into the platysma and into the submuscular aponeurotic system, the superior levator labii muscle, and the zygomaticus major muscle. They create the suspension of the upper and lower lip in the lower face.

D'Andrea and Barbaix, in a 2006 study of the perioral muscles, conducted anatomic research in 40 embalmed Caucasian specimens and compared them to magnetic resonance images of ten live subjects. They demonstrated the relations of the orbicularis oris, the perioral and buccinator muscles and the muscles' path. ${ }^{11} \mathrm{~A}$ further threedimensional magnetic resonance imaging study of the lip muscles by Olszewski et al in 2009 revealed the different structures such as adipose tissue, muscle fibers, vessels, nerves, and glandular structures. The authors described a novel, noninvasive, in vivo method for segmenting and digitally reconstructing facial muscles and demonstrated clearly the direction of muscle fibers and structures. ${ }^{12}$ The anatomic structures essential for functions such as lip closure and articulation have been well described, ${ }^{12}$ along with differences in function between normal and cleft palate lips. By observing important structures in the development of the OOM, Mooney et al, ${ }^{13}$ could perform a three-dimensional reconstruction of this muscle. ${ }^{13}$

McAlister et al demonstrated in 30 Caucasian and 24 Asian dental students the differences in the thickness of the lip levator musculature and showed an improved technique of ultrasonographic imaging of the lip levator musculature. ${ }^{14}$ They investigated the zygomaticus major muscle and the levator labii superioris muscle in order to describe orthodontic results. They characterized smile lines as "high", "medium", or "low" in terms of the relation of lip to teeth and measured the thickness of the superior levator labii and major zygomaticus muscles. They found that females had a 
higher smile line and a thicker major zygomaticus muscle than males. The OOM was not investigated in this study. ${ }^{14}$

The philtrum, a very specific and characteristic area with many intertwining structures, was investigated by Briedis and Jackson, ${ }^{15}$ who performed cadaver dissections and histological studies on the philtral region of eight adults and four fetal lips to elucidate the detailed anatomy of the OOM in the intact normal lips. They described that the OOM in pars peripheralis and pars marginalis are confined to the lip and vermilion. The muscles were found to continue to the buccinator muscle profoundly and to the facial muscles superficially, which has to be taken into account in cleft lip repair. ${ }^{15}$

Overall, these studies show interindividual variation in the perioral anatomy, which must to be taken into account and studied well when intervening in this area. Furthermore, the blood supply of the lips and perioral region is very strong and can thus result in large hematomas when injecting this area, as demonstrated in the anatomic study by Pinar et $\mathrm{al}^{5}$ and in the book Surgical Anatomy of the Face. ${ }^{6}$ These publications are well worth studying before injecting the modiolar region.

\section{Injectable fillers: injection techniques, histology, and complications}

A variety of filler materials with different molecular chain length and linkage with characteristics of hydration and degradation are available, and can be used to achieve different and natural-looking results.

In a recent in vitro/ex vivo publication, Eversole et al described the histopathologic features of soft tissue filler reactions of the lips. They state that those reactions are rare and that exact numbers of incidences are unknown. ${ }^{16}$ They investigated instances of perioral and labial foreign body reactions to a variety of injectable soft tissue fillers with the objective to identify histopathologic characteristics, allowing the pathologist to identify the injected materials. Eversole et al could identify the different materials causing foreign body reactions in vitro and concluded that soft tissue-filler reactions, or similarly foreign body-host-reactions in conjunction with the morphology of the foreign materials themselves, can be differentiated from one another microscopically. ${ }^{16}$ One can further conclude that even well-tolerated injected materials have characteristic histopathologic morphologies.

An extensive review on adverse events by Requena et al in 2011 described several different filler materials and their possible indications and adverse reactions in clinical and histopathological images of tissue biopsies after surgical removal of the filler. They state that a wide variety of cosmetic fillers are available worldwide, but the ideal filler is still missing, because all fillers known today may cause adverse reactions. Requena et al show dramatic photographs and microscopic images after augmentation, and stress the importance of thorough knowledge of anatomy before injecting. ${ }^{4}$

Investigating a new injectable hyaluronic acid (HA) filler, Juvéderm $^{\circledR}$ Volbella $^{\mathrm{TM}}$ (Allergan, Inc., Irvine, CA, USA) for use in the perioral area in 2012, Eccleston and Murphy, in a 12-month prospective, multicenter, open-label study in 60 subjects, showed the results of injecting the perioral area. They investigated the "fullness goal achievement", the look and feel of the lips, and the patients' satisfaction with the effects of treatment. Juvéderm ${ }^{\circledR}$ Volbella ${ }^{\mathrm{TM}}$ injectable HA was demonstrated to be well tolerated and to provide a smooth and natural improvement in lip fullness that lasted for up to one year. ${ }^{17}$ This is the only prospective, long-term study in HA augmentation of the lips. This filler was not yet available commercially at the time this present study was conducted.

Sarnoff et $\mathrm{al}^{18}$ and Sarnoff and Gotkin ${ }^{19}$ describe in two publications a step-by-step guide to lip augmentation as well as which filling agents to use by comparison of filling agents available at the time for lip augmentation (Restylane ${ }^{\circledR}$ [Galderma S.A., Lausanne, Switzerland], Belotero ${ }^{\circledR}$ [Merz Pharmaceuticals GmbH, Frankfurt, Germany], and Juvé$\operatorname{derm}^{\circledR}$ [Allergan Inc.]). Indications for injections were to augment the lips, to correct perioral rhytides, and to enhance overall lip appearance. The authors underline that the goal for upper lip augmentation is to create a form that harmonizes with the patient's unique features, taking into account age and ethnicity; the goal for the lower lip is to create bulk, greater prominence, and projection of the vermilion. ${ }^{18,19}$

In 2007, Ali et al published a review on perioral rejuvenation and lip augmentation. ${ }^{20}$ They state that aging of the face is a process of atrophy, most noticeable in the perioral region. They discuss rejuvenation of the perioral region, including with fillers, surgery, and facial resurfacing, as correction for this aging process. Detailed techniques for each of the approaches are outlined. Composition of the various fillers is discussed by Ali et al in conjunction with their respective outcomes and duration of effect as documented by photography. ${ }^{20}$ No special attention was paid to complications. This, in contrast, is the main topic of Weinberg and Solish's article on complications in hyaluronic fillers. They describe the most frequent and serious complications (eg, hematoma, infection, granulomata), their prevention, and treatment. ${ }^{3}$

In a meta-analysis in 2013, Cohen et al evaluated 53 publications about HA used for aesthetic soft tissue augmentation. ${ }^{21}$ They found out of 53 primary clinical reports, that the highest-quality efficacy evidence was for 
injecting the nasolabial folds in 10 randomized, blinded, split-face, comparative trials. Several randomized, blind trials supported treatment of the glabella, lips, and hands. Lower-level evidence (from studies with nonrandomized, open-label, or retrospective designs) was recorded for the nasojugal folds (tear troughs), upper eyelids, nose, infraorbital hollows, oral commissures, marionette lines, perioral rhytides, temples, and cheeks. Common adverse events across anatomic areas were pain, bruising, swelling, and redness. Serious adverse events were uncommon (eight events in eight patients of 4,605 patients in total) and were considered to be unrelated (seven events) or probably unrelated (one event) to treatment. ${ }^{21}$ Cohen et al concluded that the efficacy and safety of small- and large-gel-particle HA are well established for nasolabial folds; evidence for the glabella, lips, and hands is more limited. Preliminary reports in other anatomic regions suggest efficacy without major complications. $^{21}$

Sommer states that the so-far described injection techniques do not take the anatomic structures into account accordingly, and postulates injecting the vermilion from peripherally transcutaneously in order to avoid major bruising. ${ }^{22}$

Carruthers and Carruthers, in 2005, published an article on facial sculpting and tissue augmentation with filler material. ${ }^{23}$ They also developed a grading system for lip fullness to objectify the augmentation goal and to provide aesthetic guidelines and described their favorite techniques $^{24}$ (Table 1). They state that there are five grades of lip fullness, which range from very thin (0) to full (4) on a 5-point photonumeric rating scale designed to objectively quantify the three-dimensional fullness of the lip. ${ }^{23,24}$ This scale does not take the relation between upper and lower lip into account.

Sclafani, in 2005, described techniques of soft tissue augmentation for the management of the aging perioral complex. There are various techniques for augmenting the perioral region, such as tunnel, stamp, and depot techniques. Sclafani stresses that careful analysis of this area and appropriate treatment can harmonize these areas and produce a globally aesthetic result without surgery. ${ }^{26}$

\section{Aim of the current study}

It was our aim to define the exact position of HA in the lips and the perioral region immediately after injection and 18 days post-injection.

We also wanted to record possible complications. Although avoidance of complications is preferred, it is incumbent on the physician to have a detailed understanding of the perioral anatomy and pathophysiology as well as how to prevent and manage complications.

\section{Materials and methods}

There were ten patients initially included in this prospective pilot study. All patients presented for aesthetic augmentation of the lips and perioral area, some also demanded hydration of the lips to reduce minimal wrinkles. One patient dropped out of the study for not showing up for the follow-up exam, so nine patients were included and evaluated. After thorough history taking, photo documentation was performed. A pre-injection ultrasonography, as well as informed written consent, were obtained.

Included in this pilot study were volunteers who agreed to have the lower third of the face augmented after informed, written consent was obtained. Subjects who had undergone augmentation in the past 6 months, who had known allergies/ intolerance against lidocaine, and who suffered from coagulopathies were excluded. Dysmorphophobic and psychologically unstable persons were also excluded from undergoing injection augmentation.

The patients were injected with Juvéderm ${ }^{\circledR}$ Ultra III $^{\circledR}$ and Ultra Smile $^{\circledR}$ (Allergan, Inc.), and seven were additionally injected with unlinked HA (Juvéderm ${ }^{\circledR}$ Hydrate $^{\circledR}$; Allergan, Inc.). The exact amounts, locations, and injection techniques were recorded on a standardized documentation sheet and table (see Tables 2 and 3).

\section{Imaging}

First, photographic documentation of the face - static and in motion - was performed. The patients were photographed in the following positions/with the following instructions: static/at rest looking relaxed and straight forward; closing the eyes as if sleeping; closing the eyes firmly as if the sun were

Table I Carruthers' et al ${ }^{24}$ lip fullness grading scale

\begin{tabular}{|c|c|c|c|c|c|}
\hline Grade & 0 & $\mathbf{I}$ & 2 & 3 & 4 \\
\hline Description & Very thin & Thin & Moderately thick & Thick & Very thick \\
\hline Volume/vermilion & Small & & & & Large \\
\hline $\begin{array}{l}\text { Relation to SL (from } \\
\text { columella to chin) }\end{array}$ & Far behind SL & Moderately behind SL & Slightly behind SL & Lower lip touching SL & In line with SL \\
\hline
\end{tabular}

Abbreviation: SL, Steiner line. 
Table 2 Indications, locations, and techniques for fillers

Juvéderm Ultra III ${ }^{\circledR}\left(0.8 \mathrm{~mL}\right.$ syringe) Juvéderm Hydrate ${ }^{\circledR}$ and Ultra Smile ${ }^{\circledR}$ ( $0.55 \mathrm{~mL}$ syringe) ( $\mathrm{mL}$ syringe)

Augmentation of lip/vermilion (stamp/ Rehydration of dry lips* depot technique)

Contouring of vermilion border (funnel Small rhytides* technique)

Lifting of modiolus (funnel technique) Augmentation of philtrum*

Flattening of nasolabial fold (funnel and Augmentation of upper lip from stamp techniques) nose to vermilion border*

Note: Juvéderm ${ }^{\circledast}$ products: Allergan, Inc., Irvine, CA, USA. *Intracutaneous injection, superficial depots.

shining; kissing; smiling; showing teeth; raising eyebrows to wrinkle the forehead; raising the nasal tip as when sniffing; and looking angry.

Then, high-resolution ultrasonography of the lower third of the face was conducted. A Hitachi HI VISION Avius ${ }^{\circledR}$ ultrasound system with linear scanner (frequency range: 6-14 MHz; Hitachi Ltd, Tokyo, Japan) supplied images of the OOM and the surrounding lip tissue. Blood vessels were detected by color Doppler flow mapping with the same device in Doppler flow mode. The amount of pressure applied on the sonography head could not be standardized and thus structures were recorded in a dynamic way with varying pressures and flow documentations. A gel pad was used (Aquaflex ${ }^{\circledR}$ $1 \mathrm{~cm}$; Parker Laboratories, Fairfield, NJ, USA) for optimal ultrasonographic transmission. ${ }^{27}$

Last, slit-light optical coherence tomography (SL-OCT) of the lip surface was performed to objectify even minimal wrinkles of the lips. The SL-OCT used was a Spectralis ${ }^{\circledR}$ (Heidelberg Engineering, Heidelberg, Germany) with the Slit lamp BD $900^{\circledR}$ (Heidelberg Engineering), and background illumination with Eco-lite EL 01/02 (Haag-Streit AG (Koeniz,
Switzerland). The wave length of the diode laser beam was approx. $1310 \mathrm{~nm}$. The resulting A scans had a pattern size of $15 \times 7 \mathrm{~mm}$. We scanned both the upper and lower lip, each in 3 positions (medial, right lateral, left lateral). Thus, we obtained 6 A scans of each patient.

The examinations were performed before, immediately after, and 18 days after injection in five patients. Due to time constraints, four patients were examined only once on day 1 .

The dates of investigations were chosen as the day of the injection (before and immediately after the injection), as well as 18 days after the injection for convenience of patients and examiners.

\section{Injection techniques}

There are various techniques for augmenting tissue, such as depot technique (to augment a deep tissue on a spot), tunnel injection (by outlining a structure in linear, horizontal underlay technique), and stamp injection (injecting a deep depot, lifting the needle through the tissue to the surface while injecting, creating a vertical depot). The aim of each of these is to achieve maximum results with the least material and injury, for augmentation and wrinkle reduction with a natural-looking result.

Only sharp and non-blunt cannulas were used for injection, paramedian at both upper and lower lip in depot technique, and around the vermilion border to enhance it in tunnel technique. Further, marionette lines and deep nasolabial lines were evened out by tunnel and stamp injection techniques. All of the above were performed with Juvéderm ${ }^{\circledR}$ Ultra III $^{\circledR}$ and Ultra Smile ${ }^{\circledR}$.

Juvéderm $^{\circledR}$ Hydrate $^{\circledR}$ was deposited subcutaneously in the philtrum/upper lip area to even out small rhytides and augment the subcutaneous tissue.

Table 3 Amounts of filler material used and indications per patient

\begin{tabular}{|c|c|c|c|}
\hline Patient & Juvéderm ${ }^{\circledR}$ Ultra III $^{\circledR}$ & Juvéderm Ultra Smile ${ }^{\circledR}$ & Juvéderm Hydrate ${ }^{\circledR}$ \\
\hline I. 48 years old & $0.8 \mathrm{~mL}$, marionette lines & $0.55 \mathrm{~mL}$ UL volume, vermilion border & 0 \\
\hline 2. 45 years old & $\begin{array}{l}2 \times 0.8=1.6 \mathrm{~mL} \text {, vermilion border, } \\
\mathrm{LL} \text { volume }\end{array}$ & 0 & I mL, UL rhytides \\
\hline 3. 41 years old & $\begin{array}{l}2 \times 0.8=1.6 \mathrm{~mL} \text {, nasolabial fold, marionette } \\
\text { lines }\end{array}$ & $0.55 \mathrm{~mL}$, vermilion border & $\begin{array}{l}\text { I mL, UL rhytides, } \\
\text { philtrum }\end{array}$ \\
\hline 4. 62 years old & $\begin{array}{l}2 \times 0.8=1.6 \mathrm{~mL} \text {, nasolabial fold, marionette } \\
\text { lines }\end{array}$ & $0.55 \mathrm{~mL}$, vermilion border & I mL, UL rhytides \\
\hline 5. 59 years old & $0.8 \mathrm{~mL}$, nasolabial fold, marionette lines & 0 & I mL, UL rhytides \\
\hline 6. 66 years old & $0.8 \mathrm{~mL}$, nasolabial fold, modiolus & $0.55 \mathrm{~mL}$, vermilion border, UL volume & I mL, UL rhytides \\
\hline 7. 46 years old & 0 & $\begin{array}{l}3 \times 0.55=1.65 \mathrm{~mL} \text {, vermilion border, UL/LL volume, } \\
\text { and nasolabial fold }\end{array}$ & I mL, UL rhytides \\
\hline 8. 64 years old & $\begin{array}{l}3 \times 0.8=2.4 \mathrm{~mL} \text {, nasolabial fold, vermilion } \\
\text { border, and UL/LL lip volume }\end{array}$ & 0 & 0 \\
\hline 9. 63 years old & $\begin{array}{l}2 \times 0.8=1.6 \mathrm{~mL}, \text { nasolabial fold, } \\
\text { chin } / \text { marionette lines }\end{array}$ & $\begin{array}{l}2 \times 0.55=\mathrm{I} . \mathrm{I} \mathrm{mL} \text {, vermilion border, volume } \\
\text { depot UL/LL }\end{array}$ & 0 \\
\hline
\end{tabular}

Note: Juvéderm ${ }^{\circledR}$ products: Allergan, Inc., Irvine, CA, USA.

Abbreviations: LL, lower lip; UL, upper lip. 
Immediately after injection, patients were provided with cold $\left(10^{\circ} \mathrm{C}\right)$, moist pads to cool their injected perioral region.

A combination of these fillers was chosen to achieve best results according to the indications. Using a higher cross-linked, longer HA (Ultra III $^{\circledR}$ and Ultra Smile ${ }^{\circledR}$ [Allergen Inc.]) resulted in longer lasting, more stable results and hygroscopic effects, whereas the unlinked HA (Juvéderm ${ }^{\circledR}$ Hydrate $^{\circledR}$ ) had the most immediate rhytidereducing effects.

All fillers were used in combination and recorded in the patient's chart (see Table 3).

\section{Results}

Out of all 21 applicant patients, nine females, aged 46 to 64 years (mean 55.0 years, range 41.2-66. 1 years), were eligible to participate in this pilot study. Three women were injectable-naïve and six had previously received injectable filler augmentations of the lips and face. All were otherwise healthy, taking no medication on a regular basis (except for hormone substitution) and with no known allergies.

Figure 1 demonstrates a systematic B-mode ultrasonography of the lips, which was performed in every patient and included:

- static sonogram at five defined points;

- dynamic sonogram (from midline to right and from midline to left modiolus);

- and Doppler sonography for identification of flow and vessels.

The injected material distributed well within the lip tissue, and no embolism or thrombosis occurred in our investigated cases. The location and position of the fillers was confirmed by ultrasound in the anatomically intended spots. Some of the injected material, intended for volume augmentation of the lip, was deposited in the deep part (pars peripheralis) of the OOM. The injected material came up to $1 \mathrm{~mm}$ from the arteries and veins of the lips.

The sonography (Figure 3) shows how the HA depots lie in the OOM: one can differentiate lacunar and laminar
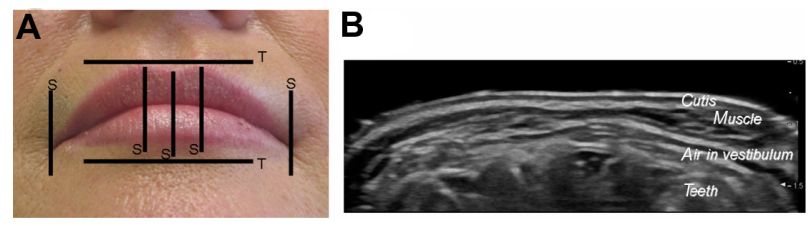

Figure I Schematic drawing of ultrasonography (static in B-mode).

Notes: (A) Schematic drawing of the static sonograms. (B) Transverse sonogram of the lower lip. The small salivary glands are depicted as round, hyper-dense areas in the subcutaneous tissue of the lips.

Abbreviations: $\mathrm{S}$, sagittal; $\mathrm{T}$, transverse.

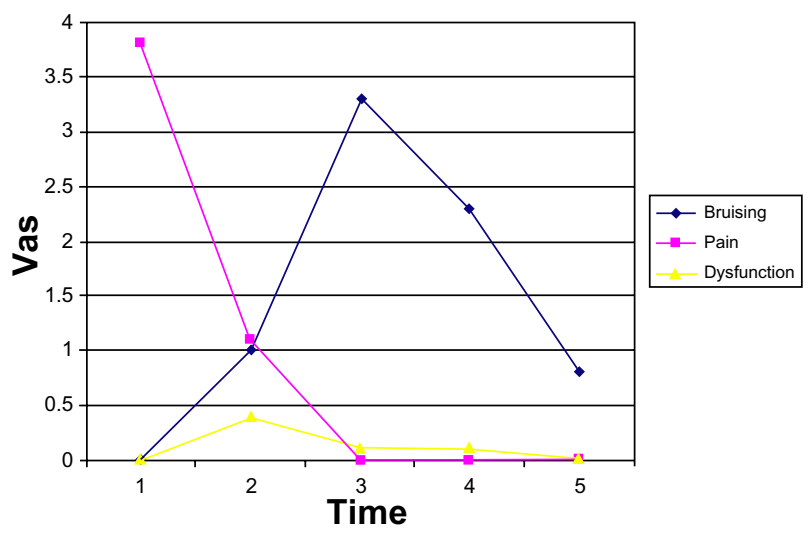

Figure 2 Patients rating of side effects after filler injection.

Notes: Adverse effects included bruising/hematoma, pain/tension, and dysfunction due to swelling, such as problems speaking, swallowing, or biting. $n=9$. VAS: selfrating $\mathrm{I}-10 \mathrm{~cm}$. Time point I: day I, during injection; time point 2: day I, 3-4 hours after injection; time point 3: day I-4 post-injection; time point 4: day 5-9 postinjection; time point 5: day 10-14 post-injection.

Abbreviation: VAS, visual analog scale.

depots, depending on the injection technique (round vesicles on depot technique, laminar and lacunar in stamp and tunnel technique). It can clearly be differentiated in the tissue directly post-injection, and merges with the tissue over time. Figure 3 shows sonographic images before and immediately after injection in a paramedian, sagittal B-mode scan of the upper lip. The muscle appears broader and thicker by the injected depots (64-year-old female). Depicted is the OOM pars superficialis and pars profunda, the latter of which is divided into pars peripheralis and pars marginalis (the shape of the muscle is akin to a hockey stick). The merging and distribution of HA with the injected tissue are ultrasonographically shown by a decontouring of depots.

The hygroscopic effect was indirectly visible by the increased volume and the decreased rhytides of the lips, as shown by OCT. The fillers were injected and thus deposited in different strata/layers (intramuscular, subcutaneously, in between the small salivary glands), which was shown by ultrasonography (see Figure 3B).

In our nine patients, no compression of lip structures such as vessels or nerves occurred, nor did any severe complications such as major bleeding, infection, or thromboembolism
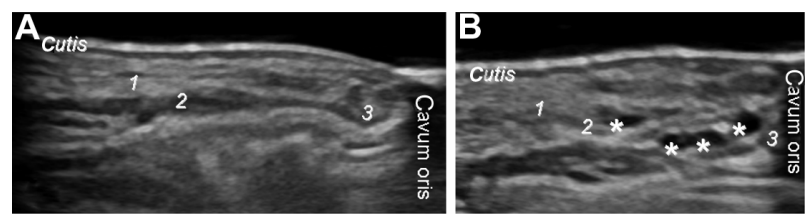

Figure 3 Pre- and post-injection ultrasonography.

Notes: Sagittal, paramedian sonogram of the upper lip pre- (A) and (B) postinjection. Orbicularis oris muscle I) pars superficialis and pars profunda, which itself is divided into 2) pars peripheralis and 3) pars marginalis. Asterisks indicate hyaluronic acid depots. The small salivary glands are depicted between cutis and muscle. 

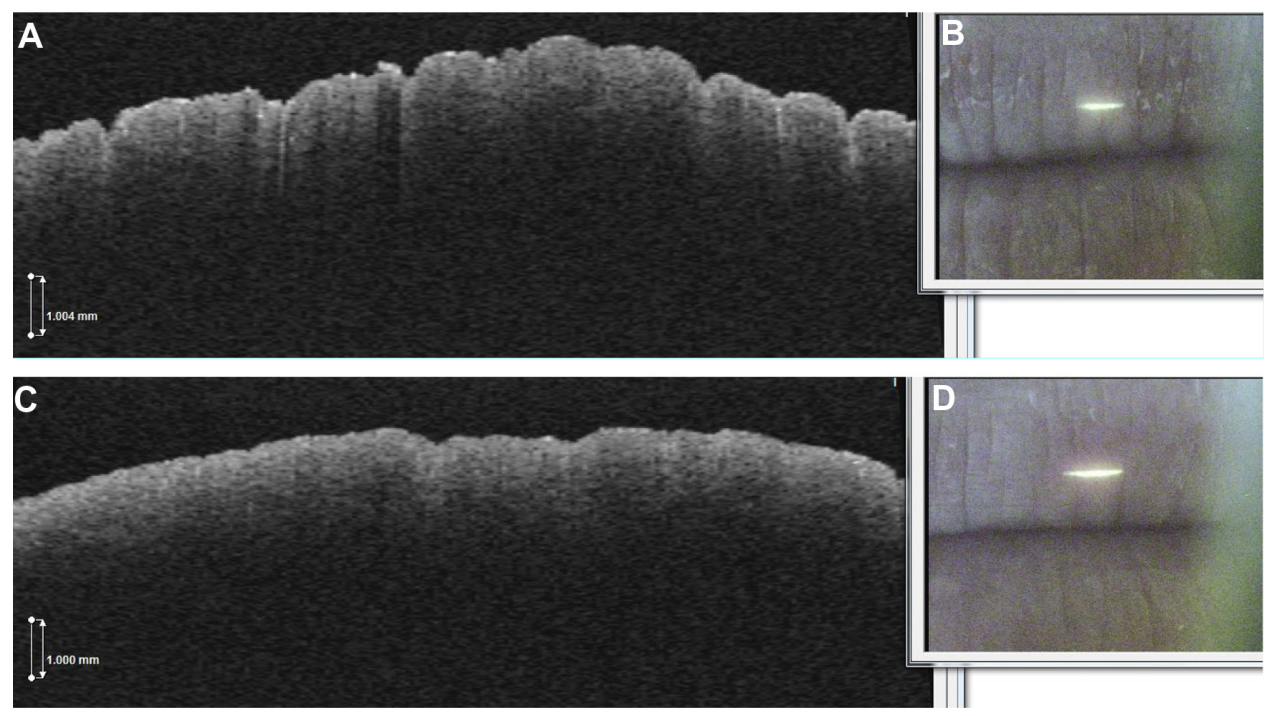

Figure 4 Optical coherence tomography imaging of the upper lip.

Notes: Patient 3's left upper lip before injection (A) and (B), and 18 days post-injection (C) and (D).

result from injection. The side effects disappeared within one week (Figure 2).

Clinically and in self-rating of the patients, the lips were smoother, more moist, and less wrinkled, which could be demonstrated and objectified by OCT as seen in Figure 4. The OCT imaging could support the scientific insight that HA saves water and can thus contribute to wetter/more hydrated and fuller lips as demonstrated by significantly reduced rhytides and scaling. The amount of augmentation achieved to a natural-looking result was rated by the Carruthers' scale and is shown in Table 4.

\section{Discussion}

There are no limits or guidelines yet as to how deep and how much substance may be injected in the human perioral region. Some authors state that the injection of hyaluronic

Table 4 Carruthers' scale grading of patients' lip fullness before and after injection

\begin{tabular}{lll}
\hline Patient & Before injection & After injection \\
\hline I. 48 years old & 0 & $\mathrm{I}$ \\
2. 45 years old & 1 & 3 \\
3. 4 I years old & 0 & 2 \\
4. 62 years old & 0 & 2 \\
5. 59 years old & 3 & 3 \\
6. 66 years old & 0 & 1 \\
7. 46 years old & 1 & 3 \\
8. 64 years old & 0 & 1 \\
9. 63 years old & 0 & 1 \\
\hline
\end{tabular}

Notes: The lip fullness can be classified into five fullness grades, ranging from very thin (0) to full (4) on a 5-point photonumeric rating scale. See Table 3 for amounts of hyaluronic acid injected. fillers should be in the superficial part of the OOM. ${ }^{28}$ Further studies must quantify the exact depth and the amount of injected filler materials by simultaneous ultrasonography during injection.

The method of ultrasonography applied in this study has an intrinsic problem, since, depending on the pressure applied with the sonic head, the structures appear differently. As such, the combination of static and dynamic investigation was essential and resulted in a good overview of the position of the injected material.

If small salivary glands are injected, retention cysts and sialadenitis can occur, but, when using resolvable HA, this has not yet been described.

It is crucial to know the exact anatomy to minimize complications and risks when injecting fillers. The position of injectables depends on the technique used, such as depot, stamp/tower, or tunnel. ${ }^{29}$ Adverse events such as bruising or thrombosis can be avoided by ultrasonographic visualization of vessels before injection and during injection control and thus early counter-action of thrombosis or compression of structures. One should always have hyaluronidase as a rescue medication at hand. When in doubt, the exact location of injected fillers should be controlled by Doppler ultrasound to avoid injury of arteries or veins; however, this is nearly impossible in a two-handed injection process.

More superficial injections could avoid injuring vessels; however, this is not always aesthetically advisable ${ }^{22}$ and does not achieve a good amount/result ratio when trying to achieve the best effect with the least material. 
Further studies to follow up at later time points after injection (eg, 3 and 6 months) would be beneficial and are in planning.

In our opinion, intramuscular injections are not absolute contraindications as stated by Lemperle et $\mathrm{al}^{28,30}$ and Lemperle and Duffy. ${ }^{31}$ Intramuscular injections may sometimes be necessary for an effective augmentation and can occur unnoticed when no ultrasonographic control is performed.

\section{Conclusion}

Common complications of the perioral region after HA augmentation such as hematoma and pain can occur in the first post-injection days, but severe bleeding, nerve injuries, thromboembolism, or even blanching, are rare.

Hyaluronidase should always be available in order to immediately be able to dissolve the filler if any crucial structures such as arteries or larger veins are compressed, injected, or blocked in order to avoid major complications with persisting damage.

Generally, HA injection is a safe and minimally invasive method by which to augment the perioral region, if one is aware of the numerous crucial anatomic structures.

It would be advantageous to locate crucial structures and the position of the injected material post-injection by ultrasound in order to avoid major complications, in case of any doubt of the position of the injected material arises, so you can "know where your fillers go" by ultrasonographic control. However, such high-end ultrasonography is not always possible, and thus such a thorough investigation may not be feasible for routine clinical application. It is desirable to raise awareness of these technical possibilities, such as high resolution ultra-sonography and OCT, and to increase their use wherever available.

\section{Acknowledgments}

Parts of the data acquired in this study were presented at the Meeting of the European Academy of Facial Plastic Surgery (EAFPS) in Rome, May 2012, and won the first prize for best e-poster presentation at the German Academy meeting for Aesthetic Surgery (GÄCD in Freiburg, 2012, and Munich, 2013) and at the Austrian Academy meeting for Otorhinolaryngology 2012 in St Pölten.

\section{Disclosure}

Injectable fillers were provided by Allergan Inc., and Dr Vent received travel support from Allergan Inc. for presenting these data at GÄCD in 2012, Freiburg, Germany. The authors report no other conflicts of interest in this work.

\section{References}

1. Beer KR. Rejuvenation of the lip with injectables. Skin Therapy Lett. 2007;12(3):5-7.

2. Wortsman X, Wortsman J, Orlandi C, Cardenas G, Sazunic I, Jemec GB. Ultrasound detection and identification of cosmetic fillers in the skin. J Eur Acad Dermatol Venereol. 2012;26(3):292-301.

3. Weinberg MJ, Solish N. Complications of hyaluronic acid fillers. Facial Plast Surg. 2009;25(5):324-328.

4. Requena L, Requena C, Christensen L, Zimmermann US, Kutzner H, Cerroni L. Adverse reactions to injectable soft tissue fillers. J Am Acad Dermatol. 2011;64(1):1-34.

5. Pinar YA, Bilge O, Govsa F. Anatomic study of the blood supply of perioral region. Clin Anat. 2005;18(5):330-339.

6. Larrabee WF Jr, Makielski KH, Henderson JL. Lips and chin. In: Surgical Anatomy of the Face. 2nd ed. Philadelphia, PA: Lipincott Williams \& Wilkins; 2004:181-186.

7. Lefarth F, Angerstein W. Sonographische Diagnostik von Narbengewebe im Muculus orbicularis oris [Diagnostic sonography in scar tissue of the Orbicularis Oris Muscle]. In: Forum Hals-, Nasen-, Ohrenheilkunde. Omnimed Verlag, Hamburg, Germany; 2013;(15):187-192. German.

8. Histology of the Lips [webpage on the Internet]. Available from: http:// www.histology.leeds.ac.uk/oral/mouth.php; 2013. May 11, 2014.

9. Tauseef O. Human lip histology slides [webpage on the Internet]. Available from: http://histology-slides-database.blogspot.de/2010/10/ human-lip-histology-slides_29.html. Lahore: King Edward Medical University Lahore; 2013. Accessed May 11, 2014.

10. Thaller SR, Kim S, Patterson H, Wildman M, Daniller A. The submuscular aponeurotic system (SMAS): a histologic and comparative anatomy evaluation. Plast Reconstr Surg. 1990;86(4):690-696.

11. D'Andrea E, Barbaix E. Anatomic research on the perioral muscles, functional matrix of the maxillary and mandibular bones. Surg Radiol Anat. 2006;28(3):261-266.

12. Olszewski R, Liu Y, Duprez T, Xu TM, Reychler H. Three-dimensional appearance of the lips muscles with three-dimensional isotropic MRI: in vivo study. Int J Comput Assist Radiol Surg. 2009;4(4):349-352.

13. Mooney MP, Siegel MI, Kimes KR, Todhunter J. Development of the orbicularis oris muscle in normal and cleft lip and palate human fetuses using three-dimensional computer reconstruction. Plast Reconstr Surg. 1988;81(3):336-345.

14. McAlister RW, Harkness EM, Nicoll JJ. An ultrasound investigation of the lip levator musculature. Eur J Orthod. 1998;20(6):713-720.

15. Briedis J, Jackson IT. The anatomy of the philtrum: observations made on dissections in the normal lip. Br J Plast Surg. 1981;34(2): 128-132.

16. Eversole R, Tran K, Hansen D, Campbell J. Lip augmentation dermal filler reactions, histopathologic features. Head Neck Pathol. 2013;7(3):241-249.

17. Eccleston D, Murphy DK. Juvéderm $\left({ }^{\circledR}\right)$ Volbella ${ }^{\mathrm{TM}}$ in the perioral area: a 12-month prospective, multicenter, open-label study. Clin Cosmet Investig Dermatol. 2012;5:167-172.

18. Sarnoff DS, Saini R, Gotkin RH. Comparison of filling agents for lip augmentation. Aesthet Surg J. 2008;28(5):556-563.

19. Sarnoff DS, Gotkin RH. Six steps to the "perfect" lip. J Drugs Dermatol. 2012;11(9):1081-1088.

20. Ali MJ, Ende K, Maas CS. Perioral rejuvenation and lip augmentation. Facial Plast Surg Clin North Am. 2007;15(4):491-500, vii.

21. Cohen JL, Dayan SH, Brandt FS, et al. Systematic review of clinical trials of small- and large-gel-particle hyaluronic acid injectable fillers for aesthetic soft tissue augmentation. Dermatol Surg. 2013;39(2):205-231.

22. Sommer B. Die "unsichtbare" Lippenaugmentation. Schöne Lippen: Die segmentale Injektionstechnik. [The "invisible" lip augmentation. Beautiful lips: the segmental injection technique]. Kosmetische Medizin. 2012;33(1):16-21. German. 
23. Carruthers JD, Carruthers A. Facial sculpting and tissue augmentation. Dermatol Surg. 2005;31(11 Pt 2):1604-1612.

24. Carruthers A, Carruthers J, Hardas B, et al. A validated lip fullness grading scale. Dermatol Surg. 2008;34 Suppl 2:S161-S166.

25. Clymer MA. Evolution in techniques: lip augmentation. Facial Plast Surg. 2007;23(1):21-26.

26. Sclafani AP. Soft tissue fillers for management of the aging perioral complex. Facial Plast Surg. 2005;21(1):74-78.

27. Klucinec B. The effectiveness of the aquaflex gel pad in the transmission of acoustic energy. J Athl Train. 1996;31(4):313-317.

28. Lemperle G, Rullan PP, Gauthier-Hazan N. Avoiding and treating dermal filler complications. Plast Reconstr Surg. 2006;118(Suppl 3): 92S-107S
29. Sattler G, Sommer B. Bildatlas der ästhetischen Augmentationsverfahren mit Fillern: Dosierung, Lokalisation, Anwendung [Picture Atlas of Aesthetic Augmentation with Fillers: Dosage, Localization, Application]. 1st ed. Marburg: KVM - Der Medizinverlag; 2010. German.

30. Lemperle G, Anderson R, Knapp TR. An index for quantitative assessment of lip augmentation. Aesthet Surg J. 2010;30(3):301-310.

31. Lemperle G, Duffy DM. Treatment options for dermal filler complications. Aesthet Surg J. 2006;26(3):356-364.

\section{Publish your work in this journal}

Clinical, Cosmetic and Investigational Dermatology is an international, peer-reviewed, open access, online journal that focuses on the latest clinical and experimental research in all aspects of skin disease and cosmetic interventions. All areas of dermatology will be covered; contributions will be welcomed from all clinicians and basic science researchers globally. This journal is indexed on CAS. The manuscript management system is completely online and includes a very quick and fair peer-review system, which is all easy to use. Visit http://www.dovepress.com/testimonials.php to read real quotes from published authors.

Submit your manuscript here: http://www.dovepress.com/clinical-cosmetic-and-investigational-dermatology-journal 